\title{
The FOXL2 C134W mutation is characteristic of adult granulosa cell tumors of the ovary
}

\author{
Stacey Jamieson ${ }^{1,2}$, Ralf Butzow ${ }^{3,4}$, Noora Andersson ${ }^{3,6}$, Maria Alexiadis ${ }^{1}$, Leila Unkila-Kallio ${ }^{3,5}$, \\ Markku Heikinheimo ${ }^{3,6}$, Peter J Fuller ${ }^{1,2}$ and Mikko Anttonen ${ }^{3,5}$ \\ ${ }^{1}$ Prince Henry's Institute of Medical Research, Clayton, Victoria, Australia; ${ }^{2}$ Department of Medicine (MMC), \\ Monash University, Clayton, Victoria, Australia; ${ }^{3}$ Women's Health Research Program, Biomedicum Helsinki, \\ University of Helsinki, Helsinki, Finland; ${ }^{4}$ Department of Pathology, University of Helsinki, Helsinki, \\ Finland; ${ }^{5}$ Department of Obstetrics and Gynecology, University of Helsinki, Helsinki, Finland and \\ ${ }^{6}$ Children's Hospital, University of Helsinki, Helsinki, Finland
}

\begin{abstract}
Granulosa cell tumors of the ovary represent $\sim 5 \%$ of malignant ovarian cancers. It has recently been reported that $95-97 \%$ of adult granulosa cell tumors carry a unique somatic mutation in the FOXL2 gene. We undertook this study to verify the presence of the FOXL2 Cys134Trp mutation in two geographically independent cohorts of granulosa cell tumors and to examine the expression pattern of FOXL2 in these tumors. A total of 56 tumors with the histological diagnosis of adult granulosa cell tumor from two centers, Melbourne and Helsinki, were examined for the presence of the mutation using direct sequence analysis. Two granulosa cell tumor-derived cell lines, COV434 and KGN, three juvenile granulosa cell tumors and control tissues were also examined. The expression of the FOXL2 gene was determined using quantitative RT-PCR and/or immunohistochemistry. We found that $\mathbf{5 2}$ of the $\mathbf{5 6}$ adult granulosa cell tumors harbor the mutation, of which three were hemi/homozygous. Of the four cases with wild-type FOXL2 sequence, reappraisal suggests that three may have been misclassified at primary diagnosis. The KGN cells were heterozygous for the mutation, whereas the COV434 cells had a wildtype FOXL2 genotype. The expression levels of FOXL2 were similar across the adult granulosa cell tumors and the normal ovary controls; one mutation-negative granulosa cell tumor had high FOXL2 mRNA levels, whereas the COV434 cells and two of the three juvenile granulosa cell tumors lacked the expression of FOXL2. Our data provide confirmation of the frequent presence of the FOXL2 C134W mutation in adult granulosa cell tumors and demonstrate that the mutation is not associated with altered FOXL2 expression. The mutation analysis may be a useful tool to differentiate particularly between cell-rich diffuse granulosa cell tumors and mitotically active sex cord-stromal tumors. This unique FOXL2 mutation appears to be characteristic of adult granulosa cell tumors. Modern Pathology (2010) 23, 1477-1485; doi:10.1038/modpathol.2010.145; published online 6 August 2010
\end{abstract}

Keywords: FOXL2; granulosa cell tumor; ovarian cancer

Granulosa cell tumors of the ovary represent $\sim 5 \%$ of malignant ovarian cancers. ${ }^{1,2}$ Two distinct subtypes have been described based on clinical presentation and histological characteristics: the juvenile and the adult form. The adult form accounts for $95 \%$ of granulosa cell tumors and most

Correspondence: Dr M Anttonen, MD, PhD, Women's Health Research Program and Department of Obstetrics and Gynecology, Biomedicum 2U, University of Helsinki, PO Box 20, 00014 Helsinki, Finland, e-mail: mikko.anttonen@helsinki.fi or Professor PJ Fuller, MBBS, PhD, FRACP, Prince Henry's Institute of Medical Research, PO Box 5152, Clayton, VIC 3168, Australia, e-mail: peter.fuller@princehenrys.org

Received 15 April 2010; revised 13 May 2010; accepted 17 May 2010; published online 6 August 2010 commonly presents during the perimenopausal or early postmenopausal period. ${ }^{3}$ Granulosa cell tumors are characterized by slow, indolent growth and a tendency to late recurrence, with intervals in excess of 10 or 20 years not being uncommon. Although the prognosis is often favorable, those that recur and/or are at an advanced stage carry a poor prognosis with $\sim 80 \%$ of these patients succumbing to their disease. ${ }^{3}$

Although granulosa cell tumors seem to represent a relatively homogenous group of tumors, a molecular etiology has until recently eluded investigators. ${ }^{4}$ The molecular changes that give rise to granulosa cell tumors are likely to involve disruption of pathways that function during normal ovarian 
development to regulate granulosa cell proliferation. Indeed, granulosa cell tumors exhibit a gene expression profile consistent with that of normal proliferating granulosa cells of preantral follicles. ${ }^{5-7} \mathrm{~A}$ range of these genes, as well as genes commonly mutated in human malignancy, have been examined for mutations and/or altered expression in granulosa cell tumors without success. ${ }^{4}$ This situation abruptly changed in 2009 with the report of a somatic mutation in the FOXL2 gene (C402G; Cys134Trp) that was present in $97 \%$ of adult granulosa cell tumors. $^{8}$ The mutation was found in only one juvenile granulosa cell tumor ${ }^{8}$ and not found in a wide range of other tumors, both gonadal and non-gonadal. ${ }^{9,10}$ Curiously, diminished and/or loss of FOXL2 expression has been reported in advanced stage/aggressive juvenile granulosa cell tumors. ${ }^{11}$ In this study, we sought to confirm the presence of this mutation in two geographically independent cohorts of granulosa cell tumors and to examine the expression pattern of the FOXL2 gene in these tumors.

\section{Materials and methods}

\section{Melbourne}

\section{Human tissue samples}

Ovarian granulosa cell tumors and normal ovarian tissue were obtained initially for a study of serum inhibin levels in ovarian tumors ${ }^{12,13}$ and subsequently for studies of the molecular pathogenesis of granulosa cell tumors. ${ }^{5,14-19}$ Normal ovarian tissue was obtained from premenopausal women who had undergone elective hysterectomy with oophorectomy for a range of conditions not associated with ovarian malignancy (Supplementary Table 1). RNA from the tissue and the two granulosa cell tumorderived cell lines was extracted using the guanidine thiocyanate/cesium chloride method as described previously. ${ }^{14}$ Tissue collection was approved by the research and ethics committee of the Monash Medical Centre, and all women gave written informed consent before tissue collection.

\section{Cell lines}

The two human granulosa cell tumor-derived cell lines, COV434 and KGN, have been previously described. ${ }^{20}$ COV434 cells were maintained in DMEM and KGN cells in DMEM/F12 both supplemented with $10 \% \mathrm{FCS}$ at $37{ }^{\circ} \mathrm{C}$ in a $95 \%$ air $/ 5 \% \mathrm{CO}_{2}$ humidified incubator.

\section{Mutation analysis}

Total RNA ( $1 \mu \mathrm{g}$ ) was reverse-transcribed for $60 \mathrm{~min}$ at $50{ }^{\circ} \mathrm{C}$ in a total volume of $20 \mu \mathrm{l}$ using SuperScript III reverse transcriptase (Invitrogen, Carlsbad, CA, USA). First-strand synthesis was performed using $250 \mathrm{ng}$ random hexamers. The oligonucleotide primers (sense 5'-CACAACCTCAACGAGTGC-3', antisense $5^{\prime}$-TTGCCGGGCTGGAAGTGCG-3') and
PCR conditions used to amplify FOXL2 were those of Shah et $a l^{8}{ }^{8}$ using a Veriti ${ }^{\mathrm{TM}}$ 96-well Thermal Cycler (Applied Biosystems, Foster City, CA, USA). In all cases, an amplicon of the predicted size (182 bp) when compared with the molecular weight standards was obtained. The PCR products were purified using a QIAquick Gel Extraction Kit (Qiagen, Hilden, Germany). For each sample, forward and reverse sequences were determined using the primers described above as sequencing

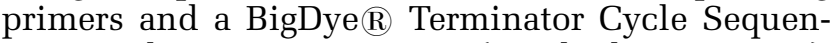
cing Ready Reaction Kit, v3.1 (Applied Biosystems), according to the manufacturer's protocol. The analysis was carried out using ABI 3130xl Genetic Analyzer (Applied Biosystems) and assembled using Sequencher 3.1.1 software. Sequencing was performed by the Gandel Charitable Trust Sequencing Centre at the Monash Health Translation Precinct, Clayton.

\section{Quantitative PCR analysis}

Quantitative PCR was performed with the oligonucleotide primers described above using an Applied Biosystems 7900HT Fast Real-Time PCR System with all reactions performed in triplicate. Cycling conditions comprised a 10 min initial denaturation step at $95{ }^{\circ} \mathrm{C}$, then 40 cycles of denaturing $\left(95^{\circ} \mathrm{C}\right.$ for $30 \mathrm{~s})$, annealing $\left(55^{\circ} \mathrm{C}\right.$ for $\left.30 \mathrm{~s}\right)$ and extension $\left(72^{\circ} \mathrm{C}\right.$ for $45 \mathrm{~s})$. The $\beta_{2}$-microglobulin $\left(\beta_{2} M\right)$ primers have been described previously. ${ }^{15}$ Yields were converted to femtograms based on the standard curve for each PCR product, and the resultant mRNA levels were normalized to the $\beta_{2} M$ mRNA level per sample. The data were calculated from the results of three independent experiments.

\section{Helsinki}

Human tissue samples

The ethical committee of the Helsinki University Central Hospital and the National Supervisory Authority for Welfare and Health in Finland approved this study. A total of 37 adult granulosa cell tumor samples were collected in Helsinki University Central Hospital between 1990 and 2009 (Supplementary Table 2). Tissue samples were snap frozen in liquid nitrogen upon the initial intraoperative diagnosis by a pathologist; the corresponding paraffin-embedded tissue samples were utilized in immunostaining. The adult granulosa cell tumor diagnosis was subsequently confirmed and tumor subtype, nuclear atypia rate and mitotic index evaluated, ${ }^{7}$ before FOXL2 mutation analysis, by an experienced pathologist (RB). Tissue samples of three ovarian carcinomas (two endometrioid and one serous) were analyzed for comparison.

\section{Mutation analysis}

DNA was extracted from frozen tissue samples with a NucleoSpin Tissue kit (Machrey Nagel, Düren, 
Germany) according to the manufacturer's instructions. The oligonucleotide PCR primers (forward 5'-CCAGTACATCATCGCGAAGTTCCCG-3' ${ }^{\prime}$, reverse $5^{\prime}$-CTCCGGCCCCGAAGAGCC-3') were those used by Shah et $a l^{8}$ for direct sequencing. For PCR amplification, $50 \mathrm{ng}$ of DNA sample was amplified with $10 \mathrm{pmol}$ of each primer, and Biotools DNA polymerase and reaction mix (Biotools, B\&M Labs, Spain) in a final volume of $15 \mu \mathrm{l}$. The thermal cycling profile consisted of a denaturing step at $94{ }^{\circ} \mathrm{C}$ for $10 \mathrm{~min}$ and then subsequently for $30 \mathrm{~s}$, annealing at $63^{\circ} \mathrm{C}$ for $30 \mathrm{~s}$ and extension at $72{ }^{\circ} \mathrm{C}$ for $30 \mathrm{~s}$ with a final incubation at $72^{\circ} \mathrm{C}$ for 5 min using a PTC-200 Peltier Thermal Cycler (MJ Research, Ramsey, MN, USA). An amplicon of the predicted size (269 bp) was obtained. The PCR products were treated with Exonuclease I (New England Biolabs, Ipswich, MA, USA) and rAPid Alkaline phosphatase (Roche Diagnostics, Mannheim, Germany), and sequenced using forward (5'-CGAAGTTCCCGTTC TACGAG-3') and reverse (described above) sequencing primers. Sequencing was performed at the Molecular Medicine Sequencing Laboratory, Biomedicum Helsinki, with an ABI 3730xl DNA Analyzer (Applied Biosystems) and assembled using Sequencher 4.9 software.

\section{Quantitative PCR analysis}

RNA was extracted from frozen tissue samples using a NucleoSpin RNA/Protein kit (Machrey Nagel) according to the manufacturer's instructions. RNA was treated with Dnase I for $10 \mathrm{~min}$ at $37^{\circ} \mathrm{C}$ and a NucleoSpin RNA Clean-Up kit (Machrey Nagel). In all, 800 ng of RNA was reverse transcribed using TaqMan reverse transcription reagents (Applied Biosystems, Branchburg, NJ, USA) and MultiScribe enzyme in $40 \mu \mathrm{l}$ volume. Quantitative PCR samples were prepared to a final volume of $20 \mu \mathrm{l}$ using Applied Biosystems SYBR Green PCR master mix, and the oligonucleotide primers for FOXL2 used were $\quad 5^{\prime}$-TTTGTCCCCTCAGTTTATTCC-3' (sense) and $5^{\prime}$-TGAATTTGGGCAGGAGACG-3' (antisense). PCR was performed using an Applied Biosystems 7900HT Fast Real-Time PCR System (Applied Biosystems) with all reactions performed in triplicate. Cycling conditions comprised a 10-min initial denaturation step at $95{ }^{\circ} \mathrm{C}$ and then 40 cycles of denaturing $\left(95^{\circ} \mathrm{C}\right.$ for $\left.15 \mathrm{~s}\right)$, annealing $\left(60^{\circ} \mathrm{C}\right.$ for $\left.15 \mathrm{~s}\right)$ and extension $\left(60^{\circ} \mathrm{C}\right.$ for $\left.15 \mathrm{~s}\right)$. The resulting mRNA levels were normalized to the $\beta$-actin mRNA level per sample (sense $5^{\prime}$-CTGACGGCCAGGTCATCAC- $3^{\prime}$ and antisense $5^{\prime}$-CAGACAGCACTGTGTTGGC-3').

\section{Immunohistochemistry}

Immunohistochemical staining of paraffin-embedded tissue samples was performed as previously described ${ }^{7}$ with primary antibodies against FOXL2 (goat polyclonal; IMG-3228, Imgenex, San Diego, CA, USA) in a dilution of $1: 400$ and $\alpha$-inhibin (mouse monoclonal; MCA 9515, AbD Serotec, Oxford, UK) in a dilution of 1:100. The results were evaluated in light microscopy by two authors (NA and MAn) as to the number of positive cells (nuclear positivity for FOXL2) and intensity of staining: - negative, + /- weak, + positive, and ++ highly positive.

\section{Results}

\section{FOXL2 C143W Mutation Status}

Employing direct sequence analysis, we examined our tumor panels for the presence of the previously reported FOXL2 C134W mutation using RNA (Melbourne) and DNA (Helsinki) extracted from frozen tissue. Collectively, 52 of 56 adult granulosa cell tumors were found to harbor the mutation (Table 1). Of the mutation-positive samples, three were hemi/ homozygous, whereas the remainder were heterozygous. Peaks of equivalent height were observed on the sequence chromatograms from the heterozygous tumors, indicating equal expression of mutant to wild-type allele where RNA was analyzed. Four tumors diagnosed as adult granulosa cell tumors were null for the mutation (Table 2). In addition, all three juvenile granulosa cell tumors, three ovarian carcinomas and 11 whole normal ovaries were mutation negative. Of the two granulosa cell tumor-derived cell lines examined, the mutation was present in the KGN cell line, as previously reported, ${ }^{9,10}$ but was absent in the COV434 cell line.

\section{Details and Evaluation of the FOXL2 Wild-Type Adult Granulosa Cell Tumor Cases}

Four adult granulosa cell tumors, two from each centre, were null for the mutation (Table 2 and Figure 1). M18 was removed from a 71-year-old woman. The pathology report described the histology as "consistent with a granulosa cell tumor of diffuse type (poorly differentiated, 'sarcomatoid').' The patient's pre-operative serum inhibin level was

Table 1 Summary of FOXL2 C134W mutation status

\begin{tabular}{|c|c|c|c|c|c|c|}
\hline \multirow[b]{3}{*}{ Tissue examined } & \multicolumn{6}{|c|}{ FOXL2 C134W mutation status } \\
\hline & \multicolumn{2}{|c|}{ Melbourne } & \multicolumn{2}{|c|}{ Helsinki } & \multicolumn{2}{|c|}{ Total } \\
\hline & Cases & $+v e$ & Cases & $+v e$ & Cases & $+v e$ \\
\hline \multicolumn{7}{|c|}{ Adult granulosa cell tumor } \\
\hline Primary & 10 & 10 & 31 & 29 & 41 & $39^{\mathrm{a}}$ \\
\hline Recurrent & 9 & 7 & 6 & 6 & 15 & $13^{\mathrm{a}}$ \\
\hline \multicolumn{7}{|c|}{ Juvenile granulosa cell tumor } \\
\hline Primary & 1 & 0 & - & - & 1 & 0 \\
\hline Recurrent & 2 & 0 & - & - & 2 & 0 \\
\hline Ovarian carcinoma & & & 3 & 0 & 3 & 0 \\
\hline Whole normal ovary & 11 & 0 & - & - & 11 & 0 \\
\hline
\end{tabular}

${ }^{\mathrm{a}}$ Of the mutation-positive adult granulosa cell tumors, one primary and two recurrent tumors were hemi/homozygous for the mutation. 
$442 \mathrm{U} / \mathrm{l}$ (postmenopausal reference range < $100 \mathrm{U} / \mathrm{l}$ ). The tumor stained strongly for $\alpha$-inhibin. This was a recurrent tumor although we do not have access to the patient's previous medical history. A re-evaluation of the morphology suggests that it should perhaps be classified as a thecoma or cellular fibroma rather than diffuse granulosa cell tumor. M19 was removed from an 80-year-old woman. The initial pathology report described a 'high grade malignant tumor with features suggestive of granulosa cell tumor, juvenile form'; however, an experienced gynecologic oncology pathologist was of the opinion that this was a 'high grade malignant tumor with features suggestive of granulosa cell tumor, adult type.' The tumor sections were positive for calreticulin and $\alpha$-inhibin immunohistochemistry and the tumor expressed high levels of FOXL2 (Figure 2a). A third opinion from an experienced gynecologist pathologist confirms the initial diagnosis of a juvenile granulosa cell tumor in a postmenopausal woman. ${ }^{21} \mathrm{H} 29$ is a primary tumor, initially diagnosed as 'diffuse or sarcomatoid form of granulosa cell tumor with moderate mitotic activity.' The tumor was $\alpha$-inhibin and FOXL2 positive (Figure 1a). In a re-evaluation of the morphology, this tumor appears in the borderline of a diffuse granulosa cell tumor and a mitotically active cellular fibroma, and given the FOXL2 mutation result, the latter appears more likely. H36 is also a primary tumor, initially diagnosed as a differentiated granulosa cell tumor and included in the ongoing prospective granulosa cell tumor study in Helsinki, being $\alpha$-inhibin positive (serum inhibin $>1000$; Figure 1b). It exhibits strong nuclear positivity for FOXL2 (Figure 1b), which is similar to the mutation-positive cases ( $\mathrm{H} 2$ as an example; Figure 1c). Upon re-examination, taking into account the FOXL2 data, the morphology still appears to be most typical of an adult granulosa cell tumor.

\section{FOXL2 mRNA and Protein Expression in Granulosa Cell Tumors}

FOXL2 mRNA levels were determined in the two adult granulosa cell tumor panels, juvenile granulosa cell tumors, granulosa cell tumor-derived cell lines and whole normal ovaries (Figure 2). The expression levels of FOXL2 determined by quantitative real-time PCR were similar across both the granulosa cell tumor panels and whole normal ovaries. In the Melbourne series, 15 adult granulosa cell tumors, three juvenile granulosa cell tumors, two granulosa cell tumor-derived cell lines and 10 whole normal ovaries were examined (Figure 2a). Although the expression levels were comparable across most adult granulosa cell tumors and normal ovary samples, high expression was observed in one of the mutation-negative adult granulosa cell tumor samples (M19). Little to no FOXL2 expression was observed in two of the three juvenile granulosa cell 
a
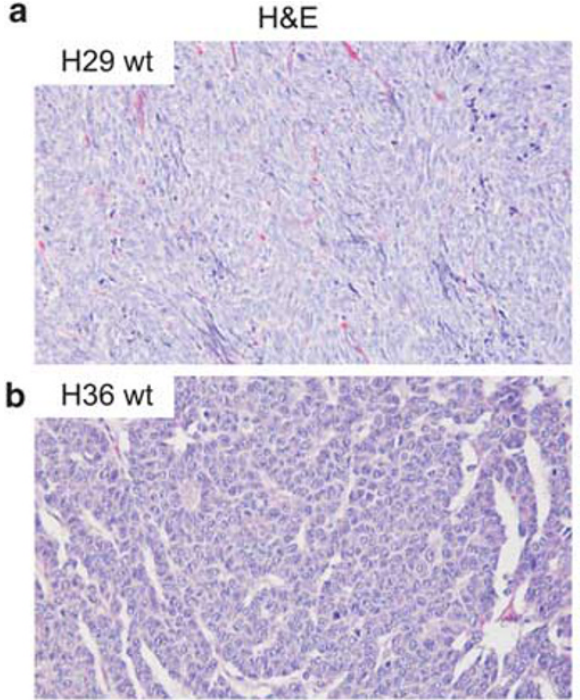

C

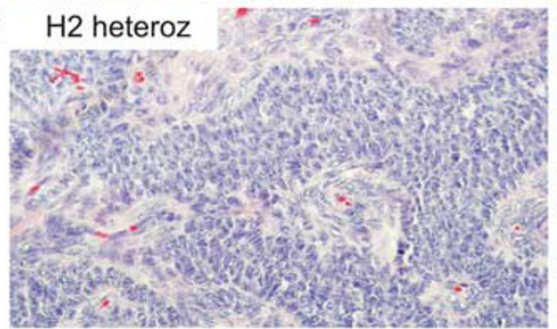

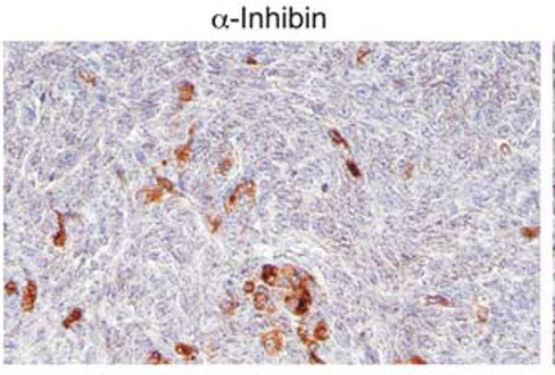
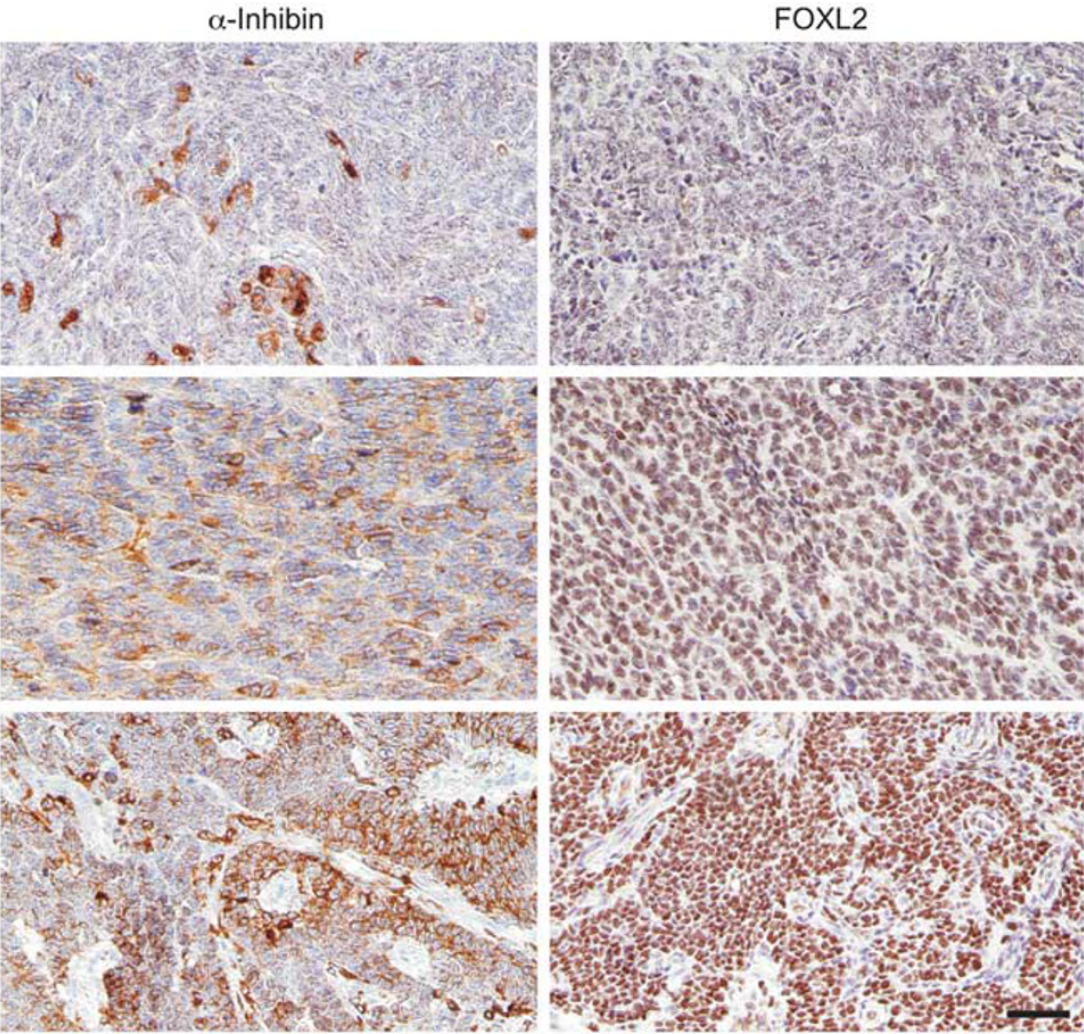

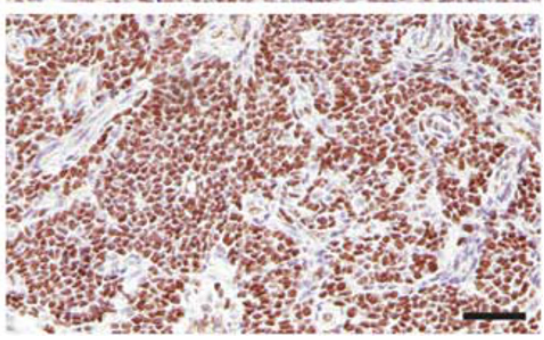

Figure 1 Histology and immunohistochemistry for $\alpha$-inhibin and FOXL2 in the Helsinki samples negative (wt) or heterozygous for the FOXL2 C143W mutation. Hematoxylin and eosin staining (left panel), immunostaining of $\alpha$-inhibin (middle panel) and FOXL2 (right panel). (a) H29, primarily a diffuse granulosa cell tumor, $\alpha$-inhibin positive, but absent or weak nuclear positivity of FOXL2. Re-diagnosed as cellular fibroma. (b) H36, a differentiated adult granulosa cell tumor upon re-evaluation of the diagnosis, with positive $\alpha$-inhibin and strong nuclear positivity of FOXL2. (c) H2, a diffuse granulosa cell tumor heterozygous for the FOXL2 C143W mutation, positive for $\alpha$-inhibin and FOXL2, similar to H36. Scale bar, $100 \mu \mathrm{m}$.

tumor samples (M20, M21 and M22) consistent with a previous report. ${ }^{11}$ The COV434 cell line was found not to express FOXL2 mRNA, which was confirmed by absent immunostaining for FOXL2 (data not shown). The relative expression levels for FOXL2 were comparable across the Helsinki series of 31 adult granulosa cell tumors with no samples exhibiting significantly higher expression (Figure $2 \mathrm{~b}$ ). Immunostaining of the 35 mutation-positive cases in Helsinki as well as the mutation-negative H36 exhibited nuclear positivity of FOXL2 in $>40 \%$ of the tumors cells, whereas H29 exhibited diffuse cytoplasmic staining and only occasionally positive nuclear staining (Figure 1 and Supplementary Table 2). There was no correlation of clinicopathological status (stage, subtype, nuclear atypia, mitotic index, inhibin staining and nuclear FOXL2 immunoreactivity) with FOXL2 mRNA levels.

\section{Discussion}

Granulosa cell tumors of the ovary are relatively uncommon neoplasms, representing approximately $5 \%$ of all ovarian malignancies. ${ }^{1,2}$ They are thought to arise from the granulosa cells of the ovary. ${ }^{22}$ Granulosa cell tumors secrete gonadal peptides including inhibin and Müllerian inhibiting substance (MIS)/anti-Müllerian hormone (AMH), and synthesize estrogen., ${ }^{4,22}$ These properties together with the gene expression profiles are characteristic of proliferating preovulatory granulosa cells. ${ }^{5-7}$ Previous studies of granulosa cell tumors have sought altered expression and/or mutations of genes expressed in normal proliferating granulosa cells, ${ }^{6}$ including transcription factors such as GATA4, ${ }^{7,23}$ and genes commonly mutated in human malignancy, ${ }^{4}$ including ras $^{16}$ and PTEN/PI3-kinase. ${ }^{19}$ Neither mutations nor robust predictors of disease have been identified, although Anttonen et $a l^{7}$ have found that high GATA-4 expression, a feature of proliferating granulosa cells, is associated with advanced stage and/or a risk of recurrence in adult granulosa cell tumors.

Using whole-transcriptome paired-end RNA sequencing of four granulosa cell tumors, Shah et $a l^{8}$ identified a single somatic, missense mutation in FOXL2 (C402G). This mutation predicts substitution of a tryptophan residue for a highly conserved cysteine residue at amino acid position 134 (Cys134Trp). ${ }^{8} \quad$ Subsequent direct sequencing of DNA from additional granulosa cell tumors revealed the mutation to be present in 86/89 (97\%) of morphologically identified adult granulosa cell 

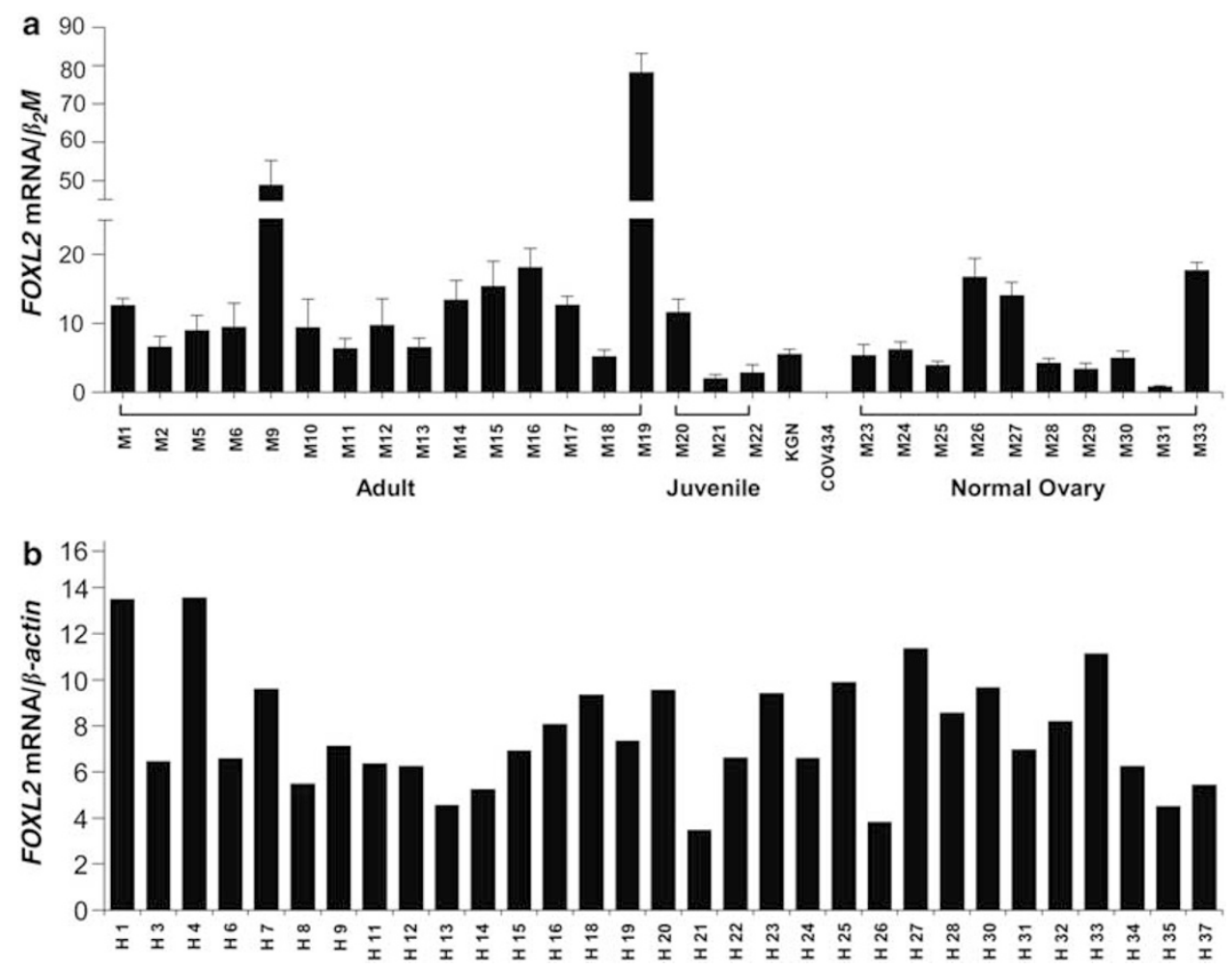

Figure 2 FOXL2 gene expression in ovarian tissue samples. Reverse-transcribed cDNA was amplified using primers specific to human FOXL2. Real-time PCR analysis was performed to determine FOXL2 mRNA expression levels. (a) Melbourne samples including adult $(n=15)$ and juvenile $(n=3)$ granulosa cell tumors, two granulosa cell tumor-derived cell lines (KGN and COV434) and normal ovarian tissue $(n=10)$. Each bar represents the mean \pm s.e.m. of three independent experiments performed in triplicate. (b) Helsinki samples include adult granulosa cell tumors $(n=31)$. Real-time PCR was performed once with triplicate samples. The FOXL2 levels are corrected for $\beta 2$-microglobulin and $\beta$-actin expression, respectively, and are expressed as a ratio.

tumors, in 1/10 (10\%) juvenile granulosa cell tumors and in $3 / 14(21 \%)$ thecomas. ${ }^{8} \mathrm{~A}$ follow-up study of other tumor types and cell lines identified the mutation as being present in the granulosa cell tumor-derived cell line, KGN, but absent in all other cell lines and tumors examined.9,10 $\mathrm{Kim}$ et $a 1^{24}$ recently reported a series of 56 adult granulosa cell tumor from Korea with 53 of the tumors harboring the FOXL2 mutation.

We examined two panels of granulosa cell tumors for the presence of the FOXL2 C134W mutation and obtained results consistent with the previous two reports, ${ }^{8,24}$ demonstrating a high frequency of the mutation. Of the mutation-positive cases, three were hemi/homozygous for the mutation. Shah et $a l^{8}$ reported three cases in which only the mutant allele was identified; it is not clear whether this represents a double somatic mutation or loss of the wild-type allele, although the latter would seem more likely. Of the four adult granulosa cell tumors negative for the mutation, one showed high levels of FOXL2 mRNA expression, which may suggest that overexpression of FOXL2 has a role in the pathogenesis of this tumor. However, it seems more likely that rather than being a variant adult granulosa cell tumor, this is an atypical juvenile granulosa cell tumor. Two other cases would appear, on reappraisal of the morphology, most likely to represent thecomas or cellular fibromas; this is consistent with the two previous reports. ${ }^{8,24}$ The one FOXL2 mutation-negative tumor that remains classified as an adult granulosa cell tumor after reevaluation exhibited true FOXL2 nuclear positivity and high serum inhibin levels. The high frequency with which the mutation occurs in adult granulosa cell tumors and its virtual absence from juvenile granulosa cell tumors and other sex cord-stromal tumor types ${ }^{8,9,24}$ argues that this FOXL2 mutation is the key characteristic of an adult-type granulosa cell tumor. Although a minority of thecomas have been reported to be FOXL2 mutation positive, ${ }^{8,24}$ these have had granulosa cell-like elements, suggesting that the distinction between these two entities should be based on both genetics and morphology. In a clinical setting, screening for the mutation is likely to be a useful diagnostic tool to differentiate the morphologically challenging tumors, particularly the diffuse adult granulosa cell tumors and the mitotically active sex-cord stromal tumors.

FOXL2 mRNA levels in adult granulosa cell tumors have not previously been examined. In this study, FOXL2 mRNA levels in the mutationpositive granulosa cell tumors were similar across the two series. Some differences were observed between tumors with respect to the number of cells expressing FOXL2, as determined by 
immunohistochemistry; however, this did not appear to associate with the stage of the disease or other clinicopathological parameters. The low FOXL2 mRNA expression observed in two of the three juvenile granulosa cell tumor cases correlates with the findings of Kalfa et $a l^{11}$ who reported FOXL2 immunohistochemistry to be decreased or absent in juvenile granulosa cell tumors with an aggressive pattern of progression. The two juvenile granulosa cell tumors with low expression exhibited metastatic and recurrent behavior, respectively, whereas the grade I juvenile granulosa cell tumor showed expression levels comparable to that of the adult-type granulosa cell tumors and normal ovaries.

The presence of the mutation in the KGN cell line, which was derived from an 81-year-old woman with recurrent metastatic disease ${ }^{25}$ is consistent with previous analyses ${ }^{9,10}$ and suggests that it may be a useful tool to study adult granulosa cell tumors. We found that the COV434 cell line, established from a metastatic granulosa cell tumor removed from a 27 year-old female, ${ }^{26,27}$ lacked the FOXL2 mutation and did not express the FOXL2 gene. This strongly suggests that the COV434 cell line is derived from a juvenile granulosa cell tumor.

The FOXL2 gene encodes a member of the forkhead domain/winged-helix family of transcription factors and has a crucial role in ovarian development and maintenance. Patients carrying inactivating mutations in the FOXL2 gene display blepharophimosis/ptosis/epicanthus inversus syndrome (BPES), an autosomal dominant disease associated with eyelid defects and premature ovarian failure in females. ${ }^{28}$ Conditional deletion of FOXL2 in transgenic mice results in transdifferentiation of the postnatal ovary into a testis, ${ }^{29}$ indicating a fundamental role for FOXL2 in defining female gonadal development and function. A number of targets of FOXL2 have been identified in both pituitary ${ }^{30}$ and gonadal cells. ${ }^{31}$ In the ovary, these include a number of genes fundamental to granulosa cell function and the development of ovarian follicles, including growth differentiation factor 9 (GDF9), inhibin $\beta$ A (INHBA) and MIS. ${ }^{32}$ The regulation of gene expression by FOXL2 involves interactions with other transcription factors including nuclear receptors and the SMAD family of transcription factors; ${ }^{33,34}$ both have fundamental roles in ovarian biology.

The Cys134Trp mutation in FOXL2 may be etiologic in adult granulosa cell tumors, but the mechanism by which it contributes to the pathogenesis of this disease remains to be determined. Given that the mutation is universal in adult granulosa cell tumors, it does not, of course, provide prognostic information. The mutation lies in the 'wing 2' domain of the forkhead DNA-binding domain of the FOXL2 protein, in a residue that is highly conserved across species. It appears unlikely to compromise DNA binding but may influence the interaction with other transcription factors. ${ }^{8}$ The mutant might be postulated to be either an activating mutation or a gain-of-function mutation. In an initial in vitro assay, Benayoun et $a l^{10}$ found limited evidence to support activation. Given the high homology with other members of the FOX family, several of which also have fundamental roles in ovarian function, such as $\mathrm{FOXO} 3 \mathrm{a},{ }^{35}$ a gain of function is a distinct possibility. Benayoun et $a l^{36}$ have argued that FOXL2 is a tumor-suppressor gene based on their findings in juvenile granulosa cell tumors. ${ }^{11}$ Considering that decreased FOXL2 expression is a feature of advanced disease in juvenile GCT, ${ }^{11}$ and therefore not etiologic, it may be a 'bystander' rather than a 'driver.' ${ }^{37}$ With the exception of four cases, we found no evidence of loss of the wild-type FOXL2 allele in the adult granulosa cell tumors as would be expected for a tumorsuppressor gene. The presence of a single, specific mutation would seem rather more analogous to the situation seen for other oncogenic or pro-proliferative mutations.

The finding of the FOXL2 C134W mutation as an almost universal feature of adult granulosa cell tumors, ${ }^{8,24}$ which we have confirmed in this study from two centers, is an exciting advance in clinical molecular oncology, but many questions remain to be resolved. At a molecular level, the consequence of the mutation remains to be determined. This information may be important if tailored therapeutics are to be developed for granulosa cell tumors, as they have been for other uncommon malignancies where a single molecular mechanism has been identified. The frequency with which the FOXL2 mutation occurs in adult granulosa cell tumors suggests that it is a potential therapeutic target. However, specificity to FOXL2 and/or the mutant form may be difficult given the large number ( 100) of highly homologous members of the FOX family of transcription factors. Screening for this novel mutation will be key to separating ovarian stromal tumors that will benefit from the putative tailored therapy, in addition to being a tool in the differential diagnostics of sex cord-stromal tumors. The major clinical challenge in the management of adult granulosa cell tumors remains in the treatment of recurrent or advanced disease for which prognostic markers and novel therapeutic targets are needed.

\section{Acknowledgements}

We (in Helsinki) thank Dr Anna-Kaisa Anttonen for generous help in the direct sequencing analysis, and Taru Jokinen for excellent technical assistance. This study was supported by research grants from the Academy of Finland (to $\mathrm{MH}$ and MAn), Helsinki University Central Hospital Research Funds (to RB LU-K, MH and MAn), Sigrid Juselius Foundation (to $\mathrm{MH}$ ) and Finnish Cancer Organizations (to $\mathrm{MH}$ ). The Melbourne group was supported by grants-in-aid 
from the Cancer Council of Victoria, the National Australia Bank Ovarian Cancer Research Foundation, the Granulosa Cell Tumour of the Ovary Foundation, the National Health and Medical Research Council of Australia through a Senior Principal Research Fellowship (to PJF) and a Dora Lush Biomedical Postgraduate Research Scholarship (441132; to SJ). Prince Henry's Institute is supported by the Victorian Government's Operational Infrastructure Support Program. SJ was also supported by the Monash University through a Faculty of Medicine Postgraduate Excellence Award.

\section{Disclosure/conflict of interest}

The authors declare no conflict of interest.

\section{References}

1 Schumer ST, Cannistra SA. Granulosa cell tumor of the ovary. J Clin Oncol 2003;21:1180-1189.

2 Colombo N, Parma G, Zanagnolo V, et al. Management of ovarian stromal cell tumors. J Clin Oncol 2007;25:2944-2951.

3 Young RH, Scully RE. Endocrine tumours of the ovary. Curr Top Pathol 1992;85:114-164.

4 Jamieson S, Fuller PJ. Management of granulosa cell tumour of the ovary. Curr Opin Oncol 2008;20: 560-564.

5 Chu S, Rushdi S, Zumpe ET, et al. FSH-regulated gene expression profiles in ovarian tumours and normal ovaries. Mol Hum Reprod 2002;8:426-433.

6 Fuller PJ, Chu S. Signalling pathways in the molecular pathogenesis of ovarian granulosa cell tumours. Trends Endocrinol Metab 2004;15:122-128.

7 Anttonen M, Unkila-Kallio L, Leminen A, et al. High GATA-4 expression associates with aggressive behavior, whereas low anti-Mullerian hormone expression associates with growth potential of ovarian granulosa cell tumors. J Clin Endocrinol Metab 2005;90: 6529-6535.

8 Shah SP, Kobel M, Senz J, et al. Mutation of FOXL2 in granulosa-cell tumors of the ovary. N Engl J Med 2009;360:2719-2729.

9 Schrader KA, Gorbatcheva B, Senz J, et al. The specificity of the FOXL2 c.402C $>$ G Somatic mutation: a survey of solid tumors. PLoS ONE 2009;4:e7988.

10 Benayoun BA, Caburet S, Dipietromaria A, et al. Functional exploration of the adult ovarian granulosa cell tumor-associated somatic FOXL2 mutation p.Cys134Trp (c.402C > G). PLoS ONE 2010;5:e8789.

11 Kalfa N, Philibert P, Patte C, et al. Extinction of FOXL2 expression in aggressive ovarian granulosa cell tumors in children. Fertil Steril 2007;87:896-901.

12 Healy DL, Burger HG, Mamers P, et al. Elevated serum inhibin concentrations in postmenopausal women with ovarian tumors. N Engl J Med 1993;329: 1539-1542.

13 Jobling T, Mamers P, Healy DL, et al. A prospective study of inhibin in granulosa cell tumors of the ovary. Gynecol Oncol 1994;55:285-289.
14 Fuller PJ, Chu S, Jobling T, et al. Inhibin subunit gene expression in ovarian cancer. Gynecol Oncol 1999;73:273-279.

15 Jamieson S, Alexiadis M, Fuller PJ. Expression status and mutational analysis of the ras and B-raf genes in ovarian granulosa cell and epithelial tumors. Gynecol Oncol 2004;95:603-609.

16 Alexiadis M, Mamers P, Chu S, et al. Insulin-like growth factor, insulin-like growth factor-binding protein-4, and pregnancy-associated plasma protein-A gene expression in human granulosa cell tumors. Int J Gynecol Cancer 2006;16:1973-1979.

17 Bittinger S, Alexiadis M, Fuller PJ. Expression status and mutational analysis of the PTEN and P13K subunit genes in ovarian granulosa cell tumors. Int J Gynecol Cancer 2009;19:339-342.

18 Chu S, Alexiadis M, Fuller PJ. Expression, mutational analysis and in vitro response of imatinib mesylate and nilotinib target genes in ovarian granulosa cell tumors. Gynecol Oncol 2008;108:182-190.

19 Fuller PJ, Verity K, Shen Y, et al. No evidence of a role for mutations or polymorphisms of the folliclestimulating hormone receptor in ovarian granulosa cell tumors. J Clin Endocrinol Metab 1998;83: 274-279.

$20 \mathrm{Chu}$ S, Nishi Y, Yanase T, et al. Transrepression of estrogen receptor beta signaling by nuclear factorkappab in ovarian granulosa cells. Mol Endocrinol 2004;18:1919-1928.

21 Biscotti CV, Hart WR. Juvenile granulosa cell tumors of the ovary. Arch Pathol Lab Med 1989;113:40-46.

22 Fuller PJ, Chu S, Fikret S, et al. Molecular pathogenesis of granulosa cell tumours. Mol Cell Endocrinol 2002;191:89-96.

23 Kyronlahti A, Ramo M, Tamminen M, et al. GATA-4 regulates Bcl-2 expression in ovarian granulosa cell tumors. Endocrinology 2008;149:5635-5642.

24 Kim MS, Hur SY, Yoo NJ, et al. Mutational analysis of FOXL2 codon 134 in granulosa cell tumour of ovary and other human cancers. J Pathol 2010;221:147-152.

25 Nishi Y, Yanase $\mathrm{T}, \mathrm{Mu} \mathrm{Y}$, et al. Establishment and characterization of a steroidogenic human granulosalike tumor cell line, KGN, that expresses functional follicle-stimulating hormone receptor. Endocrinology 2001;142:437-445.

26 van den Berg-Bakker CA, Hagemeijer A, FrankenPostma EM, et al. Establishment and characterization of 7 ovarian carcinoma cell lines and one granulosa tumor cell line: growth features and cytogenetics. Int J Cancer 1993;53:613-620.

27 Zhang H, Vollmer M, De Geyter M, et al. Characterization of an immortalized human granulosa cell line (COV434). Mol Hum Reprod 2000;6:146-153.

28 Crisponi L, Deiana M, Loi A, et al. The putative forkhead transcription factor FOXL2 is mutated in blepharophimosis/ptosis/epicanthus inversus syndrome. Nat Genet 2001;27:159-166.

29 Uhlenhaut NH, Jakob S, Anlag K, et al. Somatic sex reprogramming of adult ovaries to testes by FOXL2 ablation. Cell 2009;139:1130-1142.

30 Ellsworth BS, Egashira N, Haller JL, et al. FOXL2 in the pituitary: molecular, genetic, and developmental analysis. Mol Endocrinol 2006;20:2796-2805.

31 Moumne L, Batista F, Benayoun BA, et al. The mutations and potential targets of the forkhead transcription factor FOXL2. Mol Cell Endocrinol 2008;282:2-11. 
32 Tuteja G, Kaestner KH. Forkhead transcription factors II. Cell 2007;131:192.

33 Ellsworth BS, Burns AT, Escudero KW, et al. The gonadotropin releasing hormone (GnRH) receptor activating sequence (GRAS) is a composite regulatory element that interacts with multiple classes of transcription factors including Smads, AP-1 and a forkhead DNA binding protein. Mol Cell Endocrinol 2003;206:93-111.

34 Park M, Shin E, Won M, et al. FOXL2 interacts with steroidogenic factor-1 (SF-1) and represses SF-1-in- duced CYP17 transcription in granulosa cells. Mol Endocrinol 2010;24:1024-1036.

35 Castrillon DH, Miao L, Kollipara R, et al. Suppression of ovarian follicle activation in mice by the transcription factor Foxo3a. Science 2003;301:215-218.

36 Benayoun BA, Kalfa N, Sultan C, et al. The forkhead factor FOXL2: a novel tumor suppressor? Biochim Biophys Acta 2010;1805:1-5.

37 Sjoblom T, Jones S, Wood LD, et al. The consensus coding sequences of human breast and colorectal cancers. Science 2006;314:268-274.

Supplementary Information accompanies the paper on Modern Pathology website (http://www.nature.com/ modpathol) 